\title{
CAPTAÇÃO DE CONTRATOS: ATIVIDADE INFORMAL ENTRE PESQUISADORES CONTRATADOS ${ }^{1}$
}

Rita de Cássia Ramos Louzada*

A atuação profissional, em qualquer área, encontra-se nos dias de hoje eivada de incertezas, em função das múltiplas transformações observadas no mundo do trabalho (Antunes, 1995; Castel, 1998, entre outros). No artigo ora resenhado, o foco recai sobre pesquisadores contratados. Logo de início obtemos a informação de que nas duas últimas décadas foi observado, no Reino Unido, um incremento de contratos fora do padrão - tempo parcial e determinado - no âmbito da academia. Este staff, consideradas as diversas áreas de conhecimento, chega hoje a 35.000 pesquisadores naquela região, e tem realizado mais de $1 / 3$ da rotina acadêmica.

A despeito desses números, a literatura sobre a pesquisa contratada naquela região não é extensa. $\mathrm{O}$ estudo desenvolvido pelos autores visou preencher esta lacuna, fornecendo dados qualitativos sobre a experiência de pesquisadores, durante os anos de 1994 e 1995. Foram realizadas 61 entrevistas, em profundidade, com cientistas sociais contratados em Universidades do Reino Unido.

Um dado importante da pesquisa, que vale destacar, é a identificação de duas formas para aquisição de conhecimento ocupacional nesse campo: um que se adquire formalmente, definido por regulamentos, regras institucionais, enfim, e outro informal, adquirido durante a atividade, sobre o qual Allen-Collinson \& Hockey se detêm. Como principais fontes de informação, na academia, são apontados os administradores e os pares, mas há o reconhecimento de que existem detalhes que permanecem privados, tácitos e resistem à explicitação e à regulamentação. Esses detalhes, pouco ou nada regulados, mostram-se, no entanto, indispensáveis ao sucesso na carreira.

Nas entrevistas, o tema mais comum relacionavase à insegurança e à imprevisibilidade do emprego. Os relatos dos pesquisadores ouvidos indicaram a existência de um continum que ia desde os mais inseguros, num extremo - sem qualquer possibilidade de prever o número de horas a trabalhar num dia - até os mais seguros, os que conseguiam financiamento de instituições por cerca de 3 anos.Foram identificados vários tipos de contrato, inserções em várias universidades e projetos. Os trabalhos envolviam freqüentemente tarefas estanques - tais como realizar entrevistas, observações, análise de dados, etc - em diferentes projetos, que, por vezes, abordavam questões muito distintas. O desconforto diante dessa situação era relativamente freqüente: havia referências à ansiedade gerada pela insegurança experimentada, a qual podia variar bastante, dependendo da biografia e das circunstâncias vividas pelos pesquisadores ${ }^{2}$.

1 Allen-Collinson, J. \& Hockey, J. (1998). Capturing contracts: informal activity among contract researchers. British Journal of Sociology of Education. 19 (4), 497-513.

* Professora do Departamento de Psicologia Social e do Desenvolvimento/UFES e Pesquisadora do Programa Organização do Trabalho e Saúde Mental/IPUB/UFRJ.

Endereço para correspondência: R. Claudio da Costa, 150, Irajá, Rio de janeiro - RJ. CEP - 21235-450. Tel/fax: (21) 33719187. E-mail: ritacrl@uol.com.br

2 O maior nível de ansiedade e preocupação foi referido por pesquisadores mais dependentes do contrato para sua subsistência. 
A aquisição do conhecimento informal foi descrito, por vários pesquisadores, como fundamental para "captação de contratos", "desenvolvimento de negócios" e para "permanecer no jogo". No sentido de assegurar o emprego era necessário, para estes sujeitos da pesquisa - além da competência técnica -, o desenvolvimento de outras atividades: deviam reconhecer que esse "trabalho extra" deveria ser feito e precisavam então atender a suas particularidades, como no relato seguinte:

Há muita diplomacia que tem que acontecer e eu não sei realmente, porque eu não fico aqui o tempo suficiente para conhecer como se joga isto. [...] . então, você sabe, é realmente difícil saber como fazer essas coisas... ${ }^{3}$

Outra informação bastante relevante, colhida junto aos sujeitos, foi a importância dada à visibilidade de suas atividades. Empreendimento difícil, no entanto, já que a própria permanência na instituição não se fazia constante: era comum, por exemplo, o desenvolvimento de tarefas fora daquele ambiente (levantamento de campo, por exemplo). Como no caso de seu ambiente institucional interno, os pesquisadores aprendiam também que a invisibilidade não trazia dividendos na busca de financiamentos ${ }^{4}$. Em função das dificuldades na captação de recursos, fazia-se mister aprender a suplementar a demanda formal por financiamento com outras atividades, que eles chamavam "trabalho em rede". Este tipo de atividade era realizado principalmente no circuito nacional e internacional de conferências, na área de atuação do pesquisador. Quando entrevistados, os sujeitos freqüentemente descreviam tal trabalho como "venda": vender idéias, vender suas teorias, sua experiência e sua habilidade para pesquisa na área.

$\mathrm{Na}$ discussão, os autores ressaltam que a maneira mais ou menos exitosa de manutenção do emprego para esses grupo de pesquisadores estava diretamente relacionada com: a capacidade de lidar com o próprio departamento/centro, com sua subcultura e com a habilidade em estabelecer relações com as instituições de fomento. Surgiram, nos relatos, indícios de que a

3 A tradução deste trecho é de responsabilidade da autora desta resenha.

4 Os autores fazem aqui um parênteses para dizer, tomando como base os dados de um relatório do Economic and Social Research Council (1996), que a competição para financiamento é muito intensa na comunidade de ciências sociais, no Reino Unido, quando comparada ao campo das ciências naturais. aprendizagem a respeito da forma como lidar com esses fatores era mais parcial e lenta onde não havia massa crítica de pares e poucos pesquisadores no staff permanente.

A despeito das tentativas recentes de melhorar as condições de trabalho desses pesquisadores no Reino Unido - através da formulação do Concordat on Contract Researchers Staff Career Manegement, 1996 -, os autores consideram que há ainda muito a conhecer sobre tão complexas histórias ocupacionais. Com base na riqueza dos dados que este artigo nos traz, poderíamos perguntar: como caracterizar a "qualidade do emprego" desses sujeitos? Seria esta uma questão relevante para o meio acadêmico? Seria esta uma variável importante e capaz de influenciar o perfil do pesquisador e de sua produção?

Essas questões podem ser úteis também para pensarmos a realidade acadêmica brasileira, já que em nosso meio - e aí temos semelhanças com o Reino Unido - se observa ausência de estudos como este de Allen-Collinson \& Hockey. Seria possível caracterizar a qualidade do emprego de pesquisadores brasileiros? Além disso, poderíamos perguntar: se este fenômeno já pode ser observado numa sociedade onde a academia tem mais tradição, o que dizer do nosso futuro, considerando, por exemplo, a expansão dos cursos de pós-graduação ${ }^{6}$ e o conseqüente aumento de pesquisadores habilitados? Nossos pesquisadores estariam destinados a viver algo semelhante? Ou, pelo contrário, teríamos a possibilidade de, refletindo criticamente sobre esse quadro, ser capazes de construir alternativas menos prejudiciais ao ensino, à pesquisa e - por que não - aos pesquisadores?

$\mathrm{O}$ artigo, enfim, é leitura obrigatória para quem se interessa por temas como trabalho/trabalhadores, atividade de pesquisa e política científica. $\mathrm{O}$ maior mérito dos autores relaciona-se ao fato de, através de metodologia qualitativa, fornecer um excelente retrato do que é, como vive e o que faz um "pesquisador contratado", este personagem que, salvo engano, não é ainda comum no meio acadêmico brasileiro.

O tema da "qualidade do emprego" tem sido estudado pelos economistas do trabalho, com controvérsias. De toda forma e seja qual for o critério utilizado, "os empregos de melhor qualidade [...] são, na média, os empregos regulares" (Salm, 1998, 181). A qualidade do emprego é categoria importante nesse campo e não se reduz a salário mas, abarca também as proteções adquiridas com determinado contrato de trabalho e o que elas possibilitam ao trabalhador.

6 Dados sobre a pós-graduação no país revelam que de 1987 a 1995 o número de cursos de pós-graduação cresceu de 355 para 616 (Loureiro, 1998). 


\section{BIBLIOGRAFIA}

Antunes, R. (1995). Adeus ao trabalho? Ensaios sobre as metamorfoses e a centralidade do mundo do trabalho. São Paulo: Cortez; Campinas: Ed. Universidade Estadual de Campinas.

Castel, R. (1998). As metamorfoses da questão social: uma crônica do salário. Petrópolis: Vozes.

Loureiro, L. V. (1998). A distribuição regional da pósgraduação no país e a atuação da CAPES. Em M. Palatnik, P. Arruda, J. Leta, F. Leite e L. de Meis (Orgs.),
A pós-graduação no Brasil. (pp. 133-141), Rio de Janeiro: Ed. UFRJ.

Salm, C. (1998). As metamorfoses do trabalho. Em J. Fiori; M. Lourenço, \& J. Noronha. (Orgs.). Globalização: $o$ fato e o mito. (pp. 173-182), Rio de Janeiro: Ed. UERJ.

Recebido em 02/04/2001

Revisado em 23/04/2001

Aceito em 30/05/2001 